\title{
Original
}

\section{Effect of Ethylene Diurea on Oxygen-induced Ischemic Retinopathy in the Neonatal Rat}

\author{
Sachiko Tomoyasu-Okamoto ${ }^{1)}$, Takako Nakanishi-UedA ${ }^{2)}$, Yuta Saito ${ }^{1)}$, \\ Toshihiko UedA ${ }^{1)}$, Hajime YasuHara ${ }^{2)}$, Ryohei $\mathrm{KoIDE}^{1)}$, \\ and Shaker A. MousA ${ }^{3)}$
}

\begin{abstract}
This study investigated the effect of N-[2-(2-oxo-1-imidazolidinyl) ethyl]-N-phenylurea (ethylene diurea, EDU) on oxygen-induced ischemic retinopathy (OIR) in a neonatal rat model. OIR was induced by maintaining daily cycles of $80 \%$ oxygen $(20.5 \mathrm{~h})$, ambient air $(0.5 \mathrm{~h})$, and a progressive return to $80 \%$ oxygen $(3 \mathrm{~h})$ for 12 days (postnatal day: P12). The rats were treated intraperitoneally with EDU $(30 \mathrm{mg} / \mathrm{kg}$ body weight $)$ or distilled water (DW) from P6 to P17. At P18, the percentage of avascular areas in the total retinal area (\% AVA) was measured, and retinal neovascularization (NV) was scored in ADPase-stained retinas. Retinal superoxide dismutase (SOD) activity in the retina was also determined by a chemiluminescence method. The mean \%AVA in the EDU-treated group $(9.3 \pm 1.7 \%, \mathrm{n}=16)$ was lower than in the DW group $(18.2 \pm 4.7 \%, \mathrm{n}=17)$. EDU did not significantly affect $\mathrm{NV}$, but significantly increased SOD activity (1.36 \pm 0.13 units / mg protein, $\mathrm{n}=4)$ compared to DW treatment $(1.04 \pm 0.01$ units $/ \mathrm{mg}$ protein, $\mathrm{n}=4$, $P=0.032)$ at P18. These results suggest that EDU treatment decreased the $\%$ AVA, accompanied by an increase in normal retinal vascular growth and/or a decrease in vessel proliferation. The increased SOD activity observed in the present study is likely to involve the EDU-mediated effects.
\end{abstract}

Key words : oxygen-induced retinopathy, EDU, superoxide dismutase, neovascularization, retina

\section{Introduction}

Oxidative stress has been linked to retinopathy of prematurity (ROP) through several mechanisms related to the oxygenation of retinal tissue ${ }^{1,2)}$. ROP is one of the most important causes of blindness and visual impairment in children ${ }^{3,4)}$, and an effective treatment is required to prevent these vision problems ${ }^{5)}$. Oxygen-induced ischemic retinopathy (OIR) in the neonatal rat provides a good model system for studying the vascular changes that occur

\footnotetext{
1) Department of Ophthalmology, Showa University School of Medicine, 1-5-8 Hatanodai, Shinagawa-ku, Tokyo 1428666, Japan.

2) Department of Pharmacology, Showa University School of Medicine.

3) The Pharmaceutical Research Institute, Albany College of Pharmacy.
} 
in $\mathrm{ROP}^{6)}$. This animal model has similarities to the oxygen stresses that preterm infants experience in modern-day neonatal intensive care units in that the affected rats develop an appearance similar to stage 3 ROP with intravitreous neovascularization $(\mathrm{NV})$ at the junction of the vascular and avascular retina. Using the OIR rat model, previous studies have shown that a high oxygen concentration inhibits vascular growth in the retina and subsequent normal oxygen concentration in the air promotes $\mathrm{NV}^{6}$. During angiogenesis in the OIR retina, several angiogenic factors have been identified including vascular endothelial growth factor (VEGF $)^{7-9)}$, VEGF receptor-1 (VEGFR-1) ${ }^{9)}$, insulin-like growth factor 1 $(\text { IFG-1 })^{9,10)}$, and matrix metalloproteinases (MMPs ${ }^{11)}$; these factors are promoted by reactive oxygen species (ROS). Superoxide dismutase (SOD) is involved in the metabolism of ROS, catalyzing the dismutation of $\mathrm{O}_{2}^{-}$to $\mathrm{H}_{2} \mathrm{O}_{2} . \quad \mathrm{H}_{2} \mathrm{O}_{2}$ is generally metabolized by peroxisomal catalase, while glutathione peroxidase metabolizes mitochondrial or cytosolic $\mathrm{H}_{2} \mathrm{O}_{2}$. Therefore, increased SOD activity may inhibit NV in the OIR retina. The experimental chemical, ethylene diurea (EDU : N-[2-(2-oxo-1-imidazolidinyl)ethyl]-N-phenylurea) was reported to protect plants from otherwise damaging doses of the air pollutant, ozone $\left(\mathrm{O}_{3}\right)^{12,13)}$. EDU promoted the activity of SOD and catalase in the leaves of a normally $\mathrm{O}_{3}$ sensitive snap bean cultivar and protected against acute and chronic foliar injuries due to $\mathrm{O}_{3}{ }^{14,15)}$. EDU has also induced SOD and catalase activity both in vitro (human gingival fibroblasts) ${ }^{16)}$ and in vivo (rat heart, liver, and lung) without adverse effects ${ }^{17)}$. This study investigated the effect of EDU on retinal NV in the OIR neonatal rat model.

\section{Materials and Methods}

All animals were cared for in accordance with the ARVO Statement for the Use of Animals in Ophthalmic and Vision Research. The Institutional Committee of Animal Care and Use at our institution approved the study protocol.

\section{Animal model}

Female Sprague-Dawley rats at 14 days gestation were purchased from CREA Japan Co., Ltd. (Tokyo, Japan). Rats were divided into two groups: room-air and oxygen-exposed. In both groups, 13 or 14 neonatal rats were kept with a mother in each cage after birth. Mother rats were rotated between the room-air and oxygen-exposed groups every two days during the experimental period. Retinal NV was induced in neonatal rats by our standard protocol $^{6)}$. The oxygen-exposed rats were exposed from birth to day 12 (postnatal day: P12) to daily cycles of $80 \%$ oxygen $(20.5 \mathrm{~h})$, room air $(0.5 \mathrm{~h})$, and then a progressive return to $80 \%$ oxygen $(3 \mathrm{~h})$. On $\mathrm{P} 12$, the oxygen-exposed rats were placed in room air until the end of experiments at P18 (Fig. 1).

\section{Treatment schedule}

The rats were treated by intraperitoneal (i.p.) injection of either $30 \mathrm{mg} / \mathrm{kg}$ EDU or 


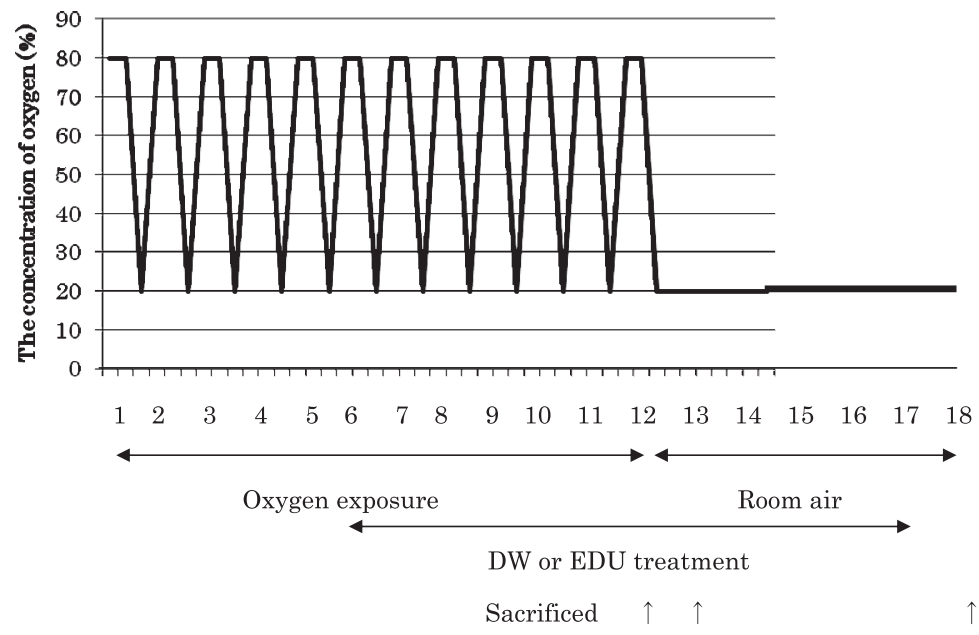

Fig. 1. The treatment schedule

distilled water (DW) in a constant volume of $50 \mu \mathrm{l} / 10 \mathrm{~g}$ body weight once daily from P6 to P17. Body weight was measured every 2 days from P0 to P18.

\section{Retinal processing and analysis}

At P18, the rats were sacrificed by i.p. injection of $0.3 \mathrm{ml}$ sodium pentobarbital $(50 \mathrm{mg} /$ $\mathrm{ml}$ ) and enucleated eyes were fixed in $4 \%$ paraformaldehyde in cacodylate buffer (0.1 M, pH7.2) for 48 hours, stained with ADPase, and flat-mounted ${ }^{6)}$. Digital images of the ADPase-stained retinas were obtained using a camera and scanner (Nikon, Tokyo, Japan), with retinal NV scored using the method of Hasebe et $a l^{18)}$. The intensity of $\mathrm{NV}$ in each retina was scored as thickened vascular long ridge: 4, short ridge: 3 , five or more glomerular buds: 2, less than five glomerular buds: 1, and none observed: 0. Avascular areas (AVAs) were also measured in the ADPase-stained retinas, with the avascular and total retinal areas measured using NIH image software (NIH, Bethesda, MD). The mean percentages of AVAs per total retinal area (\%AVAs) were calculated.

\section{Quantification of vascular endothelial growth factor (VEGF) protein and SOD activity}

Retinal samples were collected from the sacrificed rats and immersed in $100 \mu \mathrm{l}$ of tissue protein-extraction reagent (T-PER, Thermo Fisher Scientific Inc, Rockford, IL) containing a protease inhibitor cocktail (Sigma-Aldrich, St. Louis, MO; $1: 100$ ), and then stored at $-40^{\circ} \mathrm{C}$ until analysis. The samples were then cut into small pieces with scissors, sonicated in 5-s bursts at $40 \mathrm{~W}$ (Branson Sonifier Cell Disruptor 200, Branson, Rochester Hills, MI), and centrifuged at $3000 \mathrm{rpm}$ for $10 \mathrm{~min}$. VEGF in the supernatant was assayed using a rat VEGF immunoassay kit (R\&D Systems, Minneapolis, MN). SOD activity was determined by a chemiluminescence method $^{19)}$, based on the inhibition of integrated light intensity 
(A) DW treatment

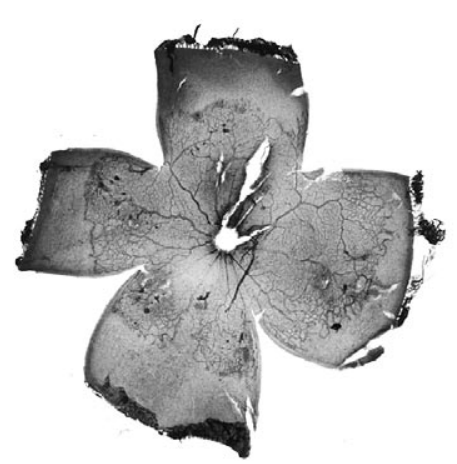

(B) EDU treatment

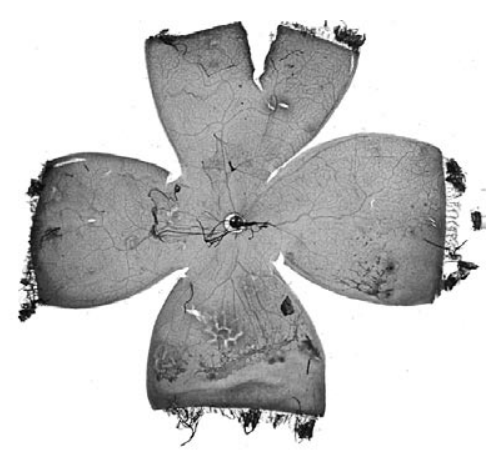

Fig. 2. Rat oxygen-induced ischemic retinopathy (OIR) model. The typical samples of flatmounted ADPase stained retinas at P18. (A) DW group, NV score is 9, \%AVA is 25.9. (B) $50 \mathrm{mg} / \mathrm{kg}$ EDU-treated group, NV score is 7, \% AVA is 11.7.

generated by $\mathrm{O}_{2}^{-}$production in biological systems. The reaction mixture contained $25 \mathrm{mM}$ 2-methyl-6-(p-methoxyphenyl)-3,7-dihydroimidazo [1,2-a] pyrazin-3-one hydrochloride (MCLA : Fluka, Tokyo), $25 \mathrm{mM}$ hypoxanthine (Sigma-Aldrich), and $3.38 \times 10^{-6}$ units xanthine oxidase (Sigma-Aldrich) in $42.5 \mathrm{mM}$ Tris buffer (Wako, Osaka), pH 7.4. Reactions were carried out at $25^{\circ} \mathrm{C}$ and the chemiluminescence was measured using a Luminescence reader BLR301 (Aloka, Tokyo).

Protein concentrations were determined using a BCA protein assay reagent kit (Thermo Fisher Scientific, Rockford, IL) using bovine serum albumin as the standard.

\section{Statistical Analysis}

Statistical analysis was performed using the Mann-Whitney U-Test. Results were considered statistically significant when the $P$ value was less than 0.05 .

\section{Results}

The body weight of rats treated with EDU increased similar to the DW-treated controls in both the room-air exposed and OIR groups. Normal retinal vascular development was observed in all animals in the room-air groups (NVs were not observed in the DW- and EDU-treated groups). OIR retinas exhibited neovascular changes and retained avascular areas (Fig. 2). In the DW- and EDU-treated groups, \%AVAs were $18.2 \pm 4.7 \% \quad(\mathrm{n}=17)$ and $9.3 \pm 1.7 \%(\mathrm{n}=16)$, respectively (Fig. 3), while $\mathrm{NV}$ scores were $6.0 \pm 0.96$ and $5.94 \pm$ 0.82, respectively (Fig. 4). The EDU treatment therefore suppressed \%AVA, but did not influence the NV extent in the OIR rat retina.

The quantity of VEGF protein in the OIR retinas increased significantly from P12 to P13 : from $71.7 \pm 15.0 \mathrm{pg} / \mathrm{mg}$ protein to $588.2 \pm 229.4 \mathrm{pg} / \mathrm{mg}$ protein in the DW group and 


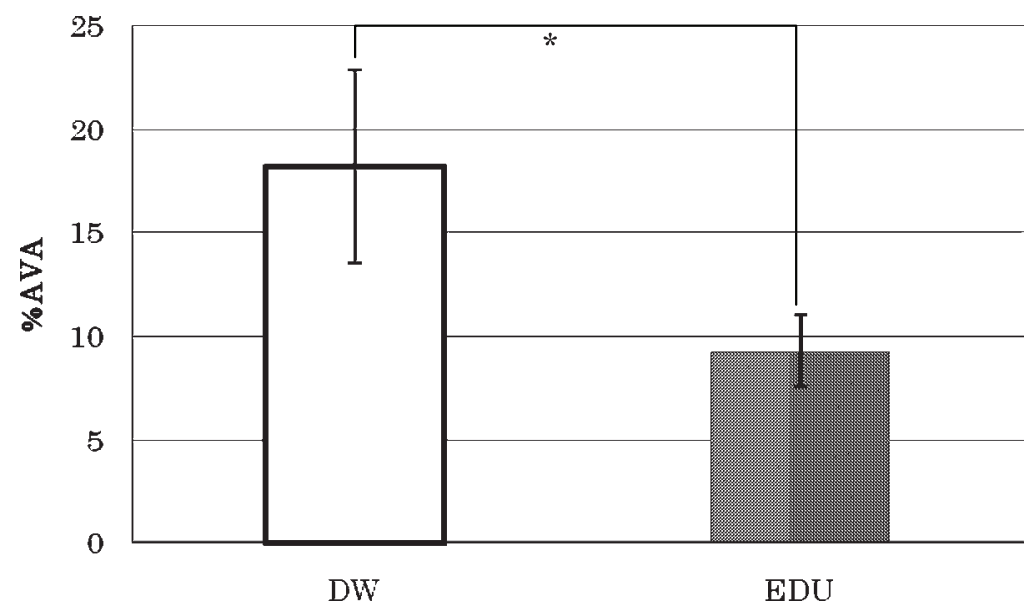

Fig. 3. Effect of $50 \mathrm{mg} / \mathrm{kg}$ EDU-treatment on \%AVA in the OIR. The open column shows \%AVA in DW group $(\mathrm{n}=17)$ and the closed column shows \%AVA in EDU treated group $(\mathrm{n}=16)$. The data represent mean $\pm \mathrm{SE}(*: \mathrm{P}<0.05)$.

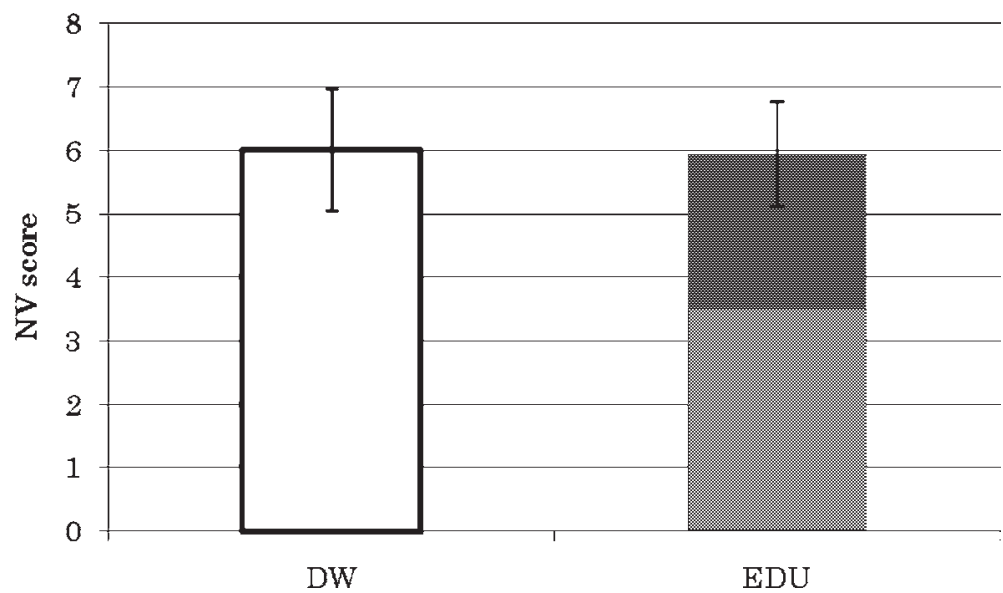

Fig. 4. Effect of $50 \mathrm{mg} / \mathrm{kg}$ EDU-treatment on NV score in the OIR. The open column shows NV score in DW group $(n=17)$ and the closed column shows NV score in EDU treated group $(n=16)$. The data represent mean \pm SE.

from $59.9 \pm 16.1 \mathrm{pg} / \mathrm{mg}$ protein to $493.7 \pm 92.9 \mathrm{pg} / \mathrm{mg}$ protein in the EDU-treated group, and at P18, it decreased to $136.7 \pm 52.3 \mathrm{pg} / \mathrm{mg}$ protein in DW group and $136.2 \pm 47.5 \mathrm{pg} /$ mg protein in the EDU-treated group (Fig. 5). In the room-air group, VEGF levels were lower than in OIR animals at each time point. In the EDU-treated group, VEGF levels were $27.2 \pm 6.3 \mathrm{pg} / \mathrm{mg}$ protein at $\mathrm{P} 12,28.0 \pm 2.9 \mathrm{pg} / \mathrm{mg}$ protein at P13, and $32.7 \pm 4.3 \mathrm{pg} /$ $\mathrm{mg}$ protein at $\mathrm{P} 18$, while in DW-treated rats the comparable values were $23.5 \pm 2.7,24.2 \pm$ 14.6 and $33.7 \pm 3.5 \mathrm{pg} / \mathrm{mg}$ protein, respectively. Thus, EDU had no effect on VEGF levels in either the OIR or room-air groups. 


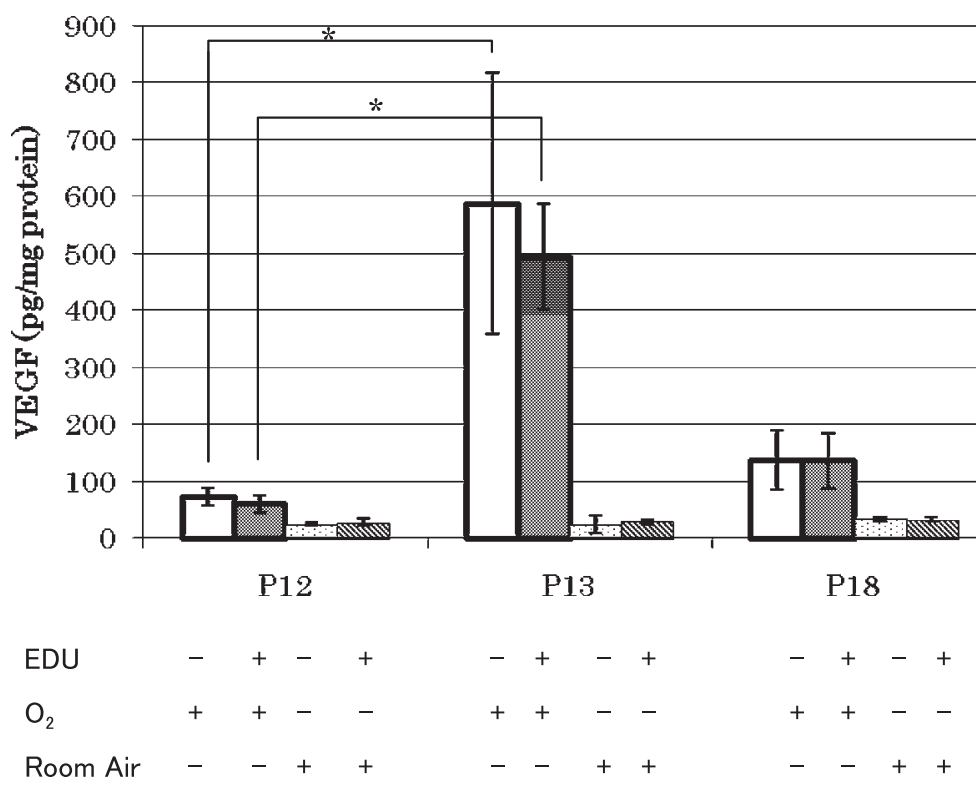

Fig. 5. Effect of EDU treatment on VEGF contents in retina. The content of VEGF significantly increased at P13 in OIR retina (open column: DW group, closed column: EDU-treated group). The spotted and the slanting line column show the contents of VEGF in DW and EDU-treated group in the room-air group. The data represent mean $\pm \mathrm{SE} \mathrm{pg} / \mathrm{mg}$ protein $\left(\mathrm{n}=3\right.$ for each point). ${ }^{*}: \mathrm{P}<0.05$ compared to the value at $\mathrm{P} 12$ in each group.

SOD activity was significantly increased in the OIR group at P18 following EDU treatment $(1.36 \pm 0.13$ units $/ \mathrm{mg}$ protein, $\mathrm{n}=3)$ compared with those treated with DW (1.04 \pm 0.01 units $/ \mathrm{mg}$ protein, $\mathrm{n}=3$ ). In the room-air group, the SOD activity was $2.09 \pm 0.26$ units / mg protein in the EDU-treated group and $1.79 \pm 0.51$ units/mg protein in the DW group at P18 (Fig. 6).

\section{Discussion}

In the present study, both \%AVAs and NV scores were significantly higher in the oxygenexposed rat retinas compared to those in room air. These findings confirmed that our OIR neonatal rat model is a suitable model for the present study ${ }^{8,20)}$.

Oxidative stress has been linked to ROP through several mechanisms related to oxygenation of retinal tissue and $\mathrm{O}_{2}^{-}$production ${ }^{1)}$. The retina is susceptible to oxidative damage given its high metabolic rate and rapid rate of oxygen consumption ${ }^{21)}$. In addition, the premature infant has a reduced ability to scavenge $\operatorname{ROS}^{22)}$, increasing its vulnerability to oxidative stress, which could also increase apoptosis and damage retinal tissues ${ }^{23)}$. The major source of $\mathrm{O}_{2}^{-}$in cells results from $\mathrm{NAD}(\mathrm{P}) \mathrm{H}$ oxidase activity. Saito et al ${ }^{24)}$ reported that the $\mathrm{NAD}(\mathrm{P}) \mathrm{H}$ oxidase inhibitor, apocyanin, reduced avascularity and apoptosis in the OIR 


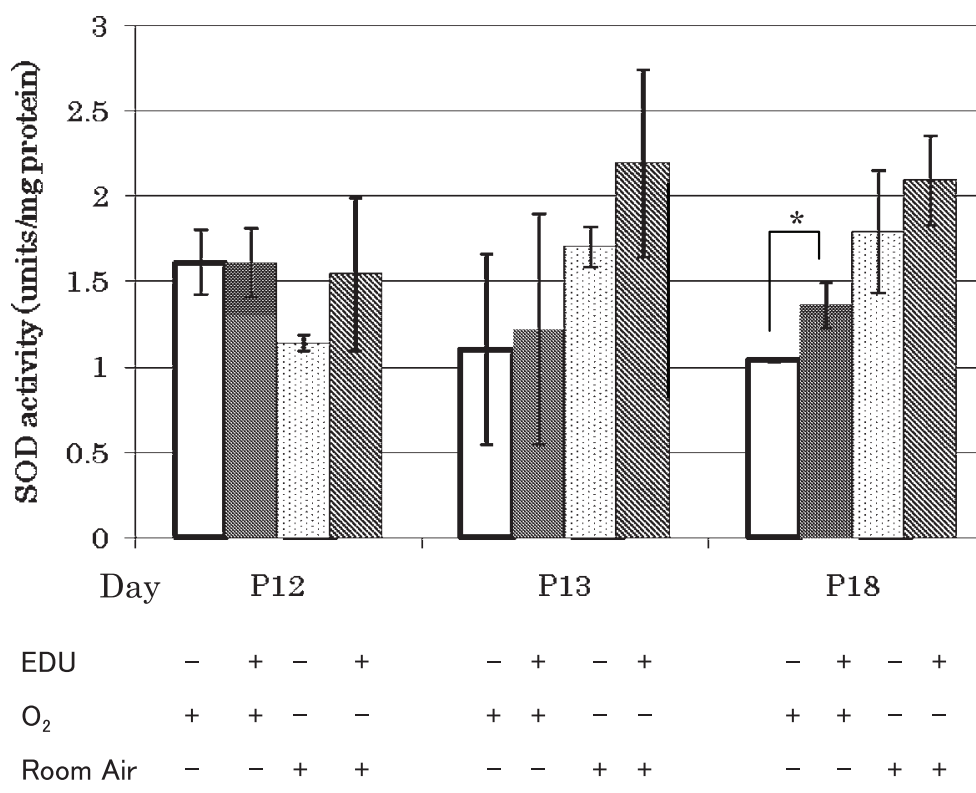

Fig. 6. Effect of EDU treatment on SOD activity in OIR and the room-air control retina. The columns are expressed as same as Fig. 5. The abscissa shows SOD activity in the retina (unit $/ \mathrm{mg}$ protein). The data represent mean $\pm \mathrm{SE}$ units $/ \mathrm{mg}$ protein $\left(\mathrm{n}=4\right.$ for each point, $\left.{ }^{*}: \mathrm{P}<0.05\right)$.

rat retina through pathways triggered by ROS generation ${ }^{24)}$. The cause of the increased $\%$ AVA in this model remains unclear. However, cleaved caspase-3 was observed at vessels in the OIR retina, which may activate apoptosis ${ }^{22}$, thereby inhibiting blood vessel growth, and increasing the \%AVA.

Exogenously administered SOD and catalase are protective in animal models of oxygenderived free radical tissue injury ${ }^{25,26)}$. In this study, SOD activity in the OIR rat retinas was increased to $131 \%$ by the EDU treatment and catalyzed $\mathrm{O}_{2}^{-}$dismutation in the retina. These data suggested that the decreased \%AVA in EDU-treated animals was due to increased $\mathrm{O}_{2}^{-}$catalysis. On the other hand, increased SOD activity leads to increased $\mathrm{H}_{2} \mathrm{O}_{2}$ generation, and thus might trigger angiogenesis ${ }^{27-29)}$. However, NV was not observed with EDU treatment in the room air-exposed rats in this study. Hence, the noted increase in SOD activity did not enhance VEGF synthesis. We speculate therefore that the increased $\mathrm{H}_{2} \mathrm{O}_{2}$ was immediately metabolized by catalase and glutathione peroxidase in the retina in this study.

ROP progresses in two phases. The first phase begins with delayed retinal vascular growth after birth in a relatively hyperoxic condition and partial regression of existing vessels, followed by a second phase of hypoxia-induced pathological vessel growth ${ }^{1)}$. We speculate that the oxygen exposure period from P1 to P12 in our OIR neonatal rat model simulated the first phase, and the subsequent normal oxygen concentration in the air period 
from P12 to P18 simulated the second phase of ROP progression. During the first phase, retinal vascular growth after birth might be enhanced by EDU treatment, due to the catalysis of $\mathrm{O}_{2}^{-}$dismutation; thus, the \%AVA in EDU-treated rats was lower than in the DW group. At P13, the levels of VEGF significantly increased in both the DW- and EDU-treatment groups by the relatively hypoxic conditions, but VEGF expression was not influenced by EDU treatment in the OIR rat retina. This phenomenon might also have resulted in the unchanged NV scores between the treatment groups. During the second phase, NV is stimulated by triggering VEGF signaling, inflammatory pathways, and TNF-alpha or other cytokines $^{30)}$, with subsequent vitreous migration. Bleeding easily occurs in these immature blood vessels and wound-healing NV starts ${ }^{31}$.

VEGF-A was also recently shown to differentially regulate angioblast sprouting behavior by promoting the expression of Notch ligand delta-like $4^{32,33)}$, which regulates the formation of the appropriate tip-cell numbers to control vessel sprouting and branching in the mouse retina ${ }^{32)}$. Notch-inhibitory gamma-secretase inhibitors raise tip-cell numbers, leading to excessive vascular sprouting and fusion without VEGF-A expression change ${ }^{32}$. Future studies should therefore focus on the cellular steps comprising the first and the second phases of ROP in the OIR model to resolve a causative mechanism.

The mechanism by which EDU induces SOD and catalase activities is unclear. EDU does not act as a scavenger of $\mathrm{O}_{2}^{-}$in the hypoxanthine and xanthine oxidase generation system in this experiment. It is interesting that EDU treatment has the potential to reduce the retinal avascular area and lead to increased retinal development in ROP.

\section{References}

1) Chen $J$ and Smith LEH : Retinopathy of prematurity. Angiogenesis 10 : 133-140 (2007)

2) Perrone S, Vessosi P, Longini M, Marzocchi B, Paffetti P, Bellieni CV, Martinelli S and Buonocore G : Biomarkers of oxidative stress in babies at high risk for retinopathy of prematurity. Front Biosci 1 : 547-552 (2009)

3) Lad EM, Hernandes-Boussard T, Morton JM and Moshfeghi DM: Incidence of retinopathy of prematurity in the United States: 1997 through 2005. Am J Ophthalmol $148: 451-458$ (2009)

4) Markova A, Jurcukova M, Dort J, Humi P, Dortova E and Horakova N : Hodnoceni rizikovych faktoru vzniku ROP, ocni vady a psychomotoricky vyvoj nedonosenych deti v zapadoceskem regionu, dvanactilete sledovani. Cesk Slov Oftalmol $65: 24-28$ (2009)

5) Mantagos IS, Vanderveen DK and Smith LE: Emerging treatments for retinopathy of prematurity. Semin Ophthalmol $24: 82-86$ (2009)

6) Reynaud $X$ and Dorey CK: Extraretinal neovascularization induced by hypoxic episodes in the neonatal rat. Invest Ophthalmol Vis Sci $35: 3169-3177$ (1994)

7) Dorey CK, Aouididi S, Reynaud X, Dvorak HF and Brown LF : Correlation of vascular permeability factor / vascular endothelial growth factor with extraretinal neovascularization in the rat. Arch Ophthalmol 114:12101217 (1996)

8) Minami M, Hasebe Y, Nakanishi-Ueda T, Iwai S, Ueda T, Dorey CK, Oguchi K, Yasuhara H and Koide R: Inhibition of oxygen-induced retinal neovascularization in the neonatal rat by green tea extract. $J$ Clin Biochem Netr $33: 23-31$ (2003)

9) Coleman RJ, Beharry KDA, Brock RS, Abad-Santos P, Abad-Santos M and Modanlou HD: Effect of brief, 
clustered versus dispersed hypoxic episodes on systemic and ocular growth factors in a rat model of oxygeninduced retinopathy. Pediatr Res $64: 50-55$ (2008)

10) Hartnett ME, Martiniuk DJ, Saito Y, Geisen P, Peterson LJ and McColm JR: Triamcinolone reduces neovascularization, capillary density and IFG-1 receptor phosphorylation in a model of oxygen-induced retinopathy. Invest Ophthalmol Vis Sci $47:$ 4975-4982 (2006)

11) Majka S, McGuire P, Colombo $S$ and Das A: The balance between proteinases and inhibitors in a murine model of proliferative retinopathy. Invest Ophthlmol Vis Sci $42: 210-215$ (2001)

12) Carnahan JE, Jenner EL and Wat EKW: Prevention of ozone injury to plants by a new protectant chemical Phytopathology $68: 1225-1229$ (1978)

13) Legassicke BC and Ormrod DP: Suppression of ozone-injury on tomatoes by ethylene diurea in controlled environments and in the field. HortSci 16:183-184 (1981)

14) Lee EH and Bennett JH: Superoxide dismutase, a possible protective enzyme against ozone injury in snap beans (Phaseolus Vulgaris L.). Plant Physiol 69 : 1444-1449 (1982)

15) Chanway CP and Runeckles VC: Effect of ethylene diure (EDU) on ozone tolerance and superoxide dismutase activity in bush bean. Environ Pollut A 35:49-56 (1984)

16) Kerr JS, Boswell GA Jr, Ackerman NR and Stevens TM: Induction of superoxide dismutase activity by paraquat or EDU in human gingival fibroblasts. Basic Life Sci $49: 695-698$ (1988)

17) Stevens TM, Boswell GA, Adler R, Ackerman NR and Kerr JS : Induction of antioxidant enzyme activities by phenylurea derivative, EDU. Toxicol Appl Pharmacol 96 : 33-42 (1988)

18) Hasebe Y, Thomson LR and Dorey CK: Pentoxifylline inhibition of vasculogenesis in the neonatal rat retina. Invest Ophthalmol Vis Sci 41:2774-2778 (2000)

19) Nakano $M$ : Determination of superoxide radical and singlet oxygen based on chemiluminescence of luciferin analogs. Methods Enzymol 186 : 585-591 (1990)

20) Saito $Y$, Hasebe-Takenaka $Y$, Ueda $T$, Nakanishi-Ueda $T$, Kosuge S, Aburada M, Shimada T, Ikeya $Y$, Onda H, Ogura H, Taguchi Y, Yasuhara $\mathrm{H}$ and Koide R: Effect of green tea fractions on oxygen-induced retinal neovascularization in the neonatal rat. J Clin Biochem Nutr 41:43-49 (2007)

21) Daeman FJ : Vertebrate rod outer segment membranes. Biochim Biophys Acta 300 : 255-288 (1973)

22) Asikainen TM, Heikkila P, Kaarteenaho-Wiik R, Kinnula VL and Raivio KO : Cell-specific expression of manganese superoxide dismutase protein in the lungs of patients with respiratory distress syndrome, chronic lung disease, or persistent pulmonary hypertension. Pediatr Pulmonol 32 : 193-200 (2001)

23) Takashi A, Masuda A, Sun M, Cetronze VE and Herman B: Oxidative stress-induced apoptosis is associated with alterations in mitochondrial caspase activity and Bcl-2-dependent alteration in mitochondrial $\mathrm{pH}(\mathrm{pHm})$. Brain Res Bull 62 : 497-504 (2004)

24) Saito $Y$, Geisen $P$, Abhineet $U$ and Hartnett ME: Inhibition of NAD $(P) H$ oxidase reduced apoptosis and avascular retina in an animal model of retinopathy of prematurity. Mol Vis 13:840-853 (2007)

25) Frank L, Yam $\mathrm{J}$ and Roberts RJ : The role of endotoxin in protection of adult rats from oxygen-induced lung toxicity. J Clin Invest $61: 269-275$ (1978)

26) Hass MS, Frank L and Massaro D: The effect of bacterial endotoxin synthesis of ( $\mathrm{Cu}, \mathrm{Zn}$ ) superoxide dismutase in lungs of oxygen-exposed rats. J Biol Chem 257 : 9379-9383 (1982)

27) Chua CC, Hamdy RC and Chua $\mathrm{BH}$ : Upregulation of vascular endothelial growth factor by $\mathrm{H}_{2} \mathrm{O}_{2}$ in rat heart endothelial cells. Free Radic Biol Med 25 : 891-897 (1998)

28) Yasuda M, Ohzeki Y, Shimizu S, Naito S, Ohtsuru A, Yamamoto T and Kuroiwa Y: Stimulation of in vitro angiogenesis by hydrogen peroxide and the relation with ETS-1 in endothelial cells. Life Sci 64:249-258 (1999)

29) Grzenkowicz-Wydra J, Cisowski J, Nakonieczna J, Zarebski A, Udilova N, Nohl H, Jozkowicz A, Podhajska $\mathrm{A}$ and Dulak $\mathrm{J}$ : Gene transfer of $\mathrm{Cu} / \mathrm{Zn}$ superoxide dismutase enhances the synthesis of vascular endothelial growth factor. Mol Cell Biochem $264:$ 169-181 (2004)

30) Armstrong D, Ueda T, Ueda T, Aljada A, Browne R, Fukuda S, Spengler R, Chou R, Hartment M, Buch P, Dandona P, Sasisekharan R and Dorey CK : Lipid hydroperoxide stimulates retinal neovascularization in rabbit 
retina through expression of tumor necrosis factor-alpha, vascular endothelial growth factor and platelet-derived growth factor. Angiogensis 2 : 93-104 (1998)

31) Chen J and Smith LEH : Retinopathy of prematurity. Angiogenesis 10 : 133-140 (2007)

32) Hellstrom M, Phng L-K, Hofmann JJ, Wallgard E, Coultas L, Lindblom P, Alva J, Nilsson AK, Karlsson L, Gaiano N, Yoon K, Rossant J, Iruela-Arispe ML, Kalen M, Gerhardt H and Betsholtz C: DII4 signalling through Notch1 regulates formation of tip cells during angiogenensis. Nature 445: 776-780 (2007)

33) Siekmann AF and Lawson ND: Notch signaling limits angiogenic cell behavior in developing zebrafish arteries. Nature 445 : 781-784 (2007)

[Received November 5, 2009 : Accepted December 18, 2009] 